\title{
A CRISE DO PROJETO FILOSÓFICO DA MODERNIDADE E O FUTURO DO ESTADO COMO ATOR INTERNACIONAL
}

\author{
Giovanni Olsson ${ }^{1}$ \\ Naína Ariana Souza \\ Tumelero ${ }^{2}$
}

\begin{abstract}
Resumo
O presente artigo objetiva estudar a construção do Projeto Filosófico da Modernidade e seus pilares, sua atual crise e seus impactos no papel do Estado como ator internacional. O trabalho analisa de que forma cada um dos pilares sustentaram a Modernidade, e como a própria construção deles deixou lacunas insanáveis no projeto, que, mesmo incompleto, tornou-se incompletável. O estudo demonstra que as transformações ocorridas nos pilares da Modernidade, com o passar dos anos, influenciaram a dinâmica internacional, e, por consequência, o papel do Estado nação. A conclusão é do sentido de que a soberania está sendo redefinida, e que as corporações estão desafiando o poder até então hegemônico dos Estados, incapaz de responder com os instrumentos tradicionais de política estatal a essas novas pretensões de poder rumo a um futuro incerto.
\end{abstract}

Palavras-Chave: Modernidade. Crise da modernidade. Ator internacional. Estado nação. Futuro do Estado.

\section{INTRODUÇÃO}

O presente artigo tem como objetivo geral analisar de que forma a crise da Modernidade impactou no papel do Estado como ator internacional.

O projeto-filosófico da Modernidade formou-se entre os séculos XVI e XVIII, no mesmo período em que emergia o capitalismo como modo de produção dominante nos países da Europa. As transformações no modo de produção, por sua vez, eram parte de um complexo e intenso processo de alteração de toda a estrutura da sociedade até então feudal, que incorporou também a nova ordenação do exercício do poder político (Estado-nação) e nova organização das relações sociais e seus fundamentos (sociedade contratual). Para a compreensão ampla das mudanças, o estudo se divide em três partes. No primeiro momento, deve-se analisar a

\footnotetext{
${ }^{1}$ Doutor em Direito (UFSC, 2006). Professor Titular do PPGS em Direito da UNOCHAPECÓ (SC). E-mail: golsson71@gmail.com

${ }^{2}$ Acadêmica do curso de Direito da Unochapecó. E-mail: naina@unochapeco.edu.br
} vol.09, n. 03, Rio de Janeiro, 2016. pp. 
constituição dos três pilares fundamentais para a sustentação da Modernidade em suas específicas configurações históricas: o Estado, a Sociedade e a Economia Liberal.

No segundo momento, cabe a análise dos fatores que levaram o projeto da Modernidade à crise, uma vez que, por tratar-se de um projeto extremamente complexo e capaz de infinitas possibilidades, desde a sua consolidação apresentou lacunas insanáveis, que foram aprofundadas pelo excesso de racionalidade e pela ascensão rápida do capitalismo.

No terceiro momento, deve ser estudado de que forma a consolidação do projeto da Modernidade e sua atual crise, expressada nas ideias de e pós-modernidade/transmodernidade, modificaram a dinâmica da sociedade internacional, e consequentemente, o papel do Estado como ator.

\section{A CONSTRUÇÃo do PROJETO FILOSÓfiCO DA MODERNIDADE}

O projeto-filosófico da modernidade formou-se entre os séculos XVI e XVIII, tendo coincidido a sua afirmação histórica com a emergência do capitalismo como modo de produção dominante nos países da Europa que integraram a primeira grande onda de industrialização (SANTOS, 1999, p. 78).

Embora sua construção decorra da convergência de inúmeros aportes teóricos, o projeto filosófico da modernidade está sustentado, conforme Santos (1999, p. 77), por dois pilares fundamentais: a regulação e a emancipação.

Ambos os pilares foram constituídos de três princípios cada, sendo o primeiro fundado pelos princípios do Estado (articulado por Hobbes); do mercado, em que domina a obra de Locke; e da comunidade, tendo a formulação centrada na filosofia política de Rousseau. $\mathrm{O}$ pilar da emancipação, por sua vez, estabelece-se por três lógicas da racionalidade: a estéticoexpressiva (da arte e da literatura), a moral-prática (da ética e do direito), e, por fim, a racionalidade cognitivo-instrumental (da ciência e da técnica) (SANTOS, 1999, p. 77).

Para que ambos os pilares se completem e sustentem o edifício da modernidade, Santos (1999, p. 77) sugere haver correspondência entre eles. Para o autor:

Estes dois pilares e seus respectivos princípios ou lógicas estão ligados por cálculos de correspondência. Assim, embora as lógicas de emancipação racional visem, no seu conjunto, orientar a vida prática dos cidadãos, cada uma delas tem um modo de inserção privilegiado no pilar de regulação.

Desta forma, tendo cada um dos princípios a sua correlação racional, a racionalidade estético-expressiva, por condensar ideias de identidade e comunhão, articula-se com o princípio da comunidade; a racionalidade moral-prática ao princípio do Estado, por definir e fazer cumprir o mínimo ético no monopólio da produção e na distribuição do direito; e a 
racionalidade cognitivo-instrumental, relacionada com o princípio do mercado, por condensar ideias de individualidade e concorrência, além da possibilidade de uma conversão da ciência em força produtiva (SANTOS, 1999, p. 77).

Por isso, o projeto filosófico da Modernidade, sustentado nas grandes transformações da transição do período Medieval, é fundamental para entender a formação do Estado, da Sociedade e da Economia neste contexto.

\section{O Estado de modelo nacional}

O Estado de modelo nacional constitui uma das mais importantes contribuições do projeto filosófico da Modernidade, na medida em que apresenta uma nova formulação de organização e de exercício do poder político da sociedade.

O esgotamento progressivo do modelo medieval abriu a oportunidade de emergência de novas relações de poder constituídas em torno da territorialidade e da afirmação da soberania externa e da supremacia interna. Nesse particular, é fundamental a contribuição de Hobbes.

Thomas Hobbes, em 1651, introduziu sua obra sobre a origem do Estado como uma criatura mitológica, o Leviatã. Para ele, se cada um dos homens que compõem uma multidão determinasse as suas ações pelos seus próprios juízos e apetites individuais, esta mesma multidão não seria capaz de defender e proteger a ninguém, nem contra o inimigo comum, nem contra as injúrias mútuas. Ainda, divergindo de opinião quanto ao melhor uso de sua força, os homens não somente deixariam de se ajudar, atrapalhando-se, mas também, por esta mesma razão, anulariam sua força, sendo facilmente subjugados por um outro grupo pequeno de homens em perfeito acordo (HOBBES, 2012, p. 137).

No tocante a este acordo e à criação do Estado, o autor afirma que:

Se pudéssemos imaginar uma grande multidão de indivíduos concordes quanto à observação da justiça e das outras leis naturais, sem um poder comum que os mantivesse a todos em atitude de respeito, poderíamos supor que todo o gênero humano fizesse o mesmo, e, então, não existiria nem seria preciso que existisse qualquer governo civil ou Estado, pois haveria paz sem sujeição alguma (HOBBES, 2012, 138).

Por ser muito difícil, se não impossível, imaginar uma grande multidão vivendo em respeito mútuo, sem governo civil ou algum tipo de Estado, é que Hobbes (2012, p. 140) explica que "é preciso designar um homem ou uma assembleia de homens para representar a todos", sendo que cada membro desta multidão deve reconhecer-se e considerar-se como autor de todos os atos que seu representante praticar. Este reconhecimento consiste na afirmação de desistir do direito de governar e si mesmo, e ceder este direito àquele homem ou àquela assembleia de homens, dando-lhe autoridade para tal (HOBBES, 2012, p. 140). 
A essência do Estado consistiria então, para Hobbes (2012, p. 140), em instituir em uma pessoa os atos de uma grande multidão, por meio de pactos recíprocos, podendo este usar a força e os meios de todos, da maneira que considerar conveniente, a fim de assegurar a paz e a defesa comum.

Assim, considera-se um Estado instituído "quando uma multidão de homens concorda e pactua que a um homem qualquer ou a uma assembleia de homens seja atribuído, pela maioria, o direito de representar a pessoa de todos eles". Isso refere-se a absolutamente todos eles, tanto aqueles que votaram a favor, quanto aqueles que votaram contra (HOBBES, 2012, p. 141).

Ao se instituir este Estado, as liberdades dos homens se modificam. Para Hobbes (2012, p. 169), o sentido próprio da palavra liberdade se dá pela ausência de oposição, ou seja, de impedimentos externos ao movimento. Desta forma, "nenhum homem é livre para resistir à força do Estado, em defesa a outrem, seja culpado ou inocente, porque essa liberdade priva o soberano dos meios para proteger seus súditos" (HOBBES, 2012, p. 177). Ele introduz, aqui, o conceito de liberdade "negativa", que será aperfeiçoado século depois.

Desta forma, a obrigação dos súditos perante o soberano permanece apenas enquanto dura o poder que serve para os proteger, constituindo a soberania, que Hobbes (2012, p. 179) afirma ser a alma do Estado, visto que separar a soberania (alma) do Estado (corpo) tiraria os movimentos de seus "membros". Esses movimentos são aquilo que se entende por "poder".

Assim, para Hobbes, o Estado que emerge na Modernidade é uma nova entidade, inédita até então, que vai integrar um povo determinado e limitado em um território, o qual vai instituir um governo soberano. Em outras palavras, é o nascimento do Estado-nação, ou Estado nacional, que vai ocupar o cenário político no globo de forma preponderante como o principal personagem e interlocutor da política, em nome da sociedade, pelos séculos seguintes.

A importância dessa nova figura conceitual é tamanha que o Estado ainda permanece sendo o protagonista da sociedade internacional e tende a se replicar isomorficamente em todos os espaços territoriais como a única entidade supostamente legítima do ponto de vista político.

\section{A Sociedade contratual}

O esgotamento do modelo Medieval, centrado em organizações de produção hierarquizadas e servis nos feudos, demandava uma nova compreensão da sociedade e a reformulação das relações sociais, em que os indivíduos e o humanismo passassem a ser o centro das reflexões e das práticas societais. Nesse aspecto, o chamado "Pilar da Comunidade" constitui uma grande novidade no cenário intelectual da época. 
No cerne do Pilar da Comunidade, encontra-se o conteúdo da obra "Contrato Social" de Rousseau, publicada em 1762. Para Rousseau, a base da comunidade é a agregação dos indivíduos reunidos por laços de sangue na família, em nossa própria família, como exemplo, já vivemos em sociedade, e esta é a mais antiga e a única sociedade natural, porque os filhos permanecem ligados ao pai somente enquanto têm necessidade dele para sua manutenção, e, ao cessar tal necessidade, esta ligação natural se dissolve. Assim, "os filhos, isentos da obediência que devem ao pai e este isento das obrigações que tem para com os filhos, voltam igualmente à independência anterior". No caso de permanecerem unidos, já não mais será naturalmente, e sim voluntariamente (ROUSSEAU, 1995, p. 70)

Deste modo, a diferença entre a família e o Estado reside em que, na primeira, o amor do pai por seus filhos é compensado pelos cuidados dedicados, já no segundo, esse amor que o chefe não tem pelo seu povo é superado pelo prazer de comandar (ROUSSEAU, 1995, p. 71).

O direito do mais forte, conforme Rousseau (1995, p.72), não é mais preponderante, porque, caso o Senhor não transforme a sua força em direito e a obediência em dever, não conseguirá permanecer no poder. É assim que se constituiu esse direito, como um direito tomado aparentemente de forma irônica, mas, na verdade, estabelecido como princípio central.

Rousseau ainda afirma: “a força é um poder físico; não vejo que a moralidade possa resultar de seus efeitos. Ceder à força é um ato de necessidade, não de vontade, no máximo, é um ato de prudência" (ROUSSEAU, 1995, p. 72). Por isso mesmo, o autor acredita que "[...] toda força que se sobrepõe à primeira, sucede-a em seu direito" (ROUSSEAU, 19995, p. 73).

Ainda, quanto à legitimação do Estado como representante da sociedade, o "Contrato Social” de Rousseau (1995, p. 78) ressalta a importância de examinar o ato pelo qual um povo é um povo, antes mesmo de examinar o ato pelo qual um povo elege um rei. Afinal, para ele, o verdadeiro fundamento da sociedade é a formação do povo.

Deste modo, Rousseau (1995, p. 78) afirma que o problema fundamental que o contrato social soluciona consiste em "encontrar uma forma de associação que defenda e proteja a pessoa e os bens de cada associado de toda a força comum, e, pela qual, cada um, unindo-se a todos, só obedeça a si mesmo, permanecendo tão livre quanto antes".

Por outro lado, o que o homem perde com o contrato social é a sua liberdade natural, aquela limitada somente pelas forças do indivíduo, além da limitação de direito a tudo o que tenta e que pode alcançar. Esta perda, porém, o faz ganhar a liberdade civil, limitada pela vontade geral, e o direito a propriedade de tudo o que possui (ROUSSEAU, 1995, p. 83).

A importância do Contrato Social está no engajamento vinculante da vontade do indivíduo a uma vontade coletiva (ROUSSEAU, 1995, p. 82): 
[...] cada indivíduo pode, como homem, ter uma vontade particular contrária ou dissoante da vontade geral, que tem como Cidadão. Seu interesse pode ser totalmente diferenciado do interesse comum;[...] Para que o pacto social não seja um acordo vão, está compreendido nele, mesmo de forma tácita, esse engajamento[...]

Essa passagem do estado de natureza ao estado civil, que rege a sociedade, acaba produzindo uma mudança muito significativa na conduta do homem ao substituir o instinto pela justiça, e dedicando às suas ações a moralidade que antes lhes faltava (ROUSSEAU, 1995, p. 82). A concepção contratualista da formação das relações sociais, ainda que possa merecer muitas críticas, constitui um notável avanço na teoria social da transição da Idade Média ao colocar o indivíduo e sua livre vontade no centro do debate, e não mais a vontade de Deus ou seus desígnios inquestionáveis. O reconhecimento de que o indivíduo pode ter vontade no espaço social, e de que esta deve ser valorizada, é essencial para a construção da dimensão democrática da sociedade moderna e contemporânea.

\section{A Economia Liberal}

A transição para a Modernidade também veio acompanhada de uma profunda transformação no modo de produção econômico. A insuficiência da estrutura Medieval dos feudos, agrária e ruralizada em relações predominantemente de troca, não dava mais conta da complexidade crescente da vida social e econômica. Nesse aspecto, a emergência do capitalismo e da classe burguesa é uma novidade importante, mas o mais significativo é a agregação de uma ideologia liberal e individualista de progresso, que vem retratada no "Pilar do Mercado".

No pilar do mercado, destacam-se as obras de Locke e Smith, tendo o primeiro baseado seus estudos no desenvolvimento teórico do liberalismo, e o segundo, tido como o pensador da economia moderna, na formação, em geral, da riqueza e sua visão utilitarista coo instrumento da consecução da felicidade geral.

Locke baseia a economia no trabalho e na propriedade, e, por isso, afirma que ainda que a Terra e todas as demais criaturas inferiores pertençam a todos os homens, cada um deve garantir e assegurar a sua propriedade, sendo que ninguém além do proprietário exercerá direito sobre ela (LOCKE, 1994, p. 98).

Por isso, a obra produzida pelo trabalho das mãos dos homens passa também a ser sua propriedade, no sentido que sempre que o homem tira um objeto colocado e deixado no Estado pela natureza e investe seu trabalho, acrescenta algo que o agrega, e, assim, isso também se torna sua propriedade (LOCKE, 1994, p. 98).

Acerca dessa diferença de valor, afirma que: 
[...] na verdade é o trabalho que estabelece em tudo a diferença de valor; basta considerar a diferença entre um acre de terra plantada com fumo ou cana, semeada com trigo ou cevada, e um acre da mesma terra deixado ao bem comum, sem qualquer cultivo, e perceberemos que a melhora realizada pelo trabalho é responsável por grandíssima parte de seu valor (LOCKE, 1994, p. 106).

Locke explica que foi desta forma que se estabeleceu o uso do dinheiro, como "alguma coisa duradoura que o homem podia guardar sem que se deteriorasse e que, por consentimento mútuo, os homens utilizariam na troca por coisas necessárias à vida, realmente úteis, mas perecíveis" (LOCKE, 1994, p. 110).

Assim, utilizando-se da ideia construída por Locke, de que o trabalho do homem sobre algo agrega valor e transforma-se posteriormente em sua propriedade, Smith delimita o conceito ao explicar de que forma a divisão do trabalho causa efeitos na economia geral da sociedade e pode contribuir para a felicidade geral guiada por uma "mão invisível".

$\mathrm{O}$ autor afirma que o maior aprimoramento das forças produtivas do trabalho, bem como a maior parte da habilidade, consciência e facilidade na direção dos trabalhos, vem dos resultados da divisão do trabalho. Para ele, "a divisão do trabalho, na medida em que pode ser introduzida, gera, em cada ofício, um aumento proporcional das forças produtivas do trabalho" (SMITH, 1996, p. 65 e 66).

Smith utiliza como exemplo uma manufatura pequena de uma fábrica de alfinetes:

Um operário não treinado para essa atividade [...] nem familiarizado com a utilização das máquinas ali empregadas [...], dificilmente poderia talvez fabricar um único alfinete em um dia, empenhando o máximo de trabalho; de qualquer forma, certamente não conseguirá fabricar vinte (SMITH, 1996 p. 65-66).

Este é um exemplo específico, mas os efeitos da divisão do trabalho são semelhantes em qualquer outro ofício e manufatura, porquanto, na medida em que a divisão do trabalho é introduzida, gera em cada ofício um aumento proporcional das forças produtivas do trabalho. E essa vantagem, mais além, influencia a diferenciação das ocupações e empregos (SMITH, 1996, p. 66).

Esse grande aumento da quantidade de trabalho que o mesmo número de pessoas é capaz de realizar em consequência dessa divisão deve-se principalmente a três circunstâncias distintas: a maior destreza do trabalhador; a economia de tempo entre um trabalho e outro; e a invenção das máquinas (SMITH, 1996, p. 68).

Em primeiro lugar, a maior destreza existente em cada trabalhador se deve à redução das atividades que cada pessoa executa para realizar alguma operação simples, sendo que esta atividade torna-se o único emprego da vida do trabalhador. Isso aumenta significativamente a 
rapidez na execução das tarefas realizadas pelo operário, superando o que uma pessoa jamais imaginaria conseguir por meio do trabalho manual (SMITH, 1996, p. 68).

Em relação à segunda circunstância, sendo impossível a troca de um tipo de trabalho a outro com muita rapidez, por questões como a logística dos diferentes lugares onde se encontram os trabalhos distintos e as ferramentas diversas utilizadas, este tempo que seria gasto para tal troca passa a ser economizado. Independendo, assim, da eficiência do operário, a troca de atividades por si só é suficiente para reduzir consideravelmente a quantidade de trabalho que ele é capaz de levar a cabo (SMITH, 1996, p. 68-69).

Por fim, a invenção de máquinas que facilitem o trabalho nas manufaturas, conforme explica Smith (1996, p. 69), é oriunda da divisão do trabalho, uma vez que, ao torna-se responsável por somente uma atividade, o operário busca formas de otimizar esta atividade. Por isso, grande parte das máquinas utilizadas nas manufaturas em que o trabalho está mais subdividido constituiu-se originalmente de invenções de operários comuns, que, com naturalidade se preocuparam em concentrar sua atenção na procura de métodos para executar a função com maior facilidade e rapidez. Desta forma, ao tornar-se cada indivíduo mais hábil em seu setor específico, o volume de trabalho a ser produzido aumenta, e, por consequência, também aumenta consideravelmente o cabedal científico (SMITH, 1996, p. 70), e, assim, a ciência coloca-se a serviço das técnicas de produção.

Enfim, e ao conectar esses três pilares, conforme explica Coelho (2007, p. 28), especialmente na Ciência Política, passa-se a utilizar o termo "Modernidade" como o conjunto de mudanças operadas nas esferas política, econômica e social, ocorridas após as revoluções burguesas, em especial a Revolução Francesa e, principalmente após a Revolução Industrial Inglesa. Em seguimento, deve-se analisar como esse projeto se desenvolveu e também atingiu pontos de esgotamento e crise.

\section{A CRISE DA MODERNIDADE}

Inúmeras expressões são utilizadas por Santos (1999, p. 77) na definição do real significado do projeto filosófico da modernidade, ou, conforme denominação do autor, o projeto sócio-cultural da modernidade. De suas obras, podem-se extrair alguns termos como "rico", "ambicioso" e "revolucionário", o que, logo de início, demonstra a complexidade do projeto, que, conforme ele mesmo explica, por sua complexidade, torna-se capaz de infinitas possibilidades e desenvolvimentos (SANTOS, 1999, p. 77). Esta mesma complexidade, porém, fez com que o projeto enfrentasse inúmeras crises. 
Na visão de Coelho (2007, p. 23), até mesmo o simples uso da palavra modernidade ocasiona certas confusões e equívocos, visto que, mesmo tratando-se originalmente de um conceito historiográfico como referência de uma época específica, a palavra acaba por ser empregada nas mais diversas conotações, tanto que praticamente todas as ciências do homem a utilizam.

No tocante a esta terminologia e, especialmente, em relação à constituição linguística do mundo, Habermas (1998, p. 311) afirma a ocorrência de uma espécie de síndrome entre os "momentos cognitivo-instrumentais, prático-morais e expressivos das funções intramundanas da linguagem especializada na exposição, da relação interpessoal e da expressão subjetiva". Ele complementa, afirmando que:

Na modernidade diferenciaram-se de cada um destes momentos $<<$ esferas de valores > - nomeadamente, a arte, a literatura e uma crítica especializada em questões de gosto sobre o eixo da abertura ao mundo, por um lado, e por outro lado discursos com a função de solucionar problemas, especializados em questões da verdade e da justiça, sobre o eixo dos processos intramundanos de aprendizagem (HABERMAS, 1998, p. 311).

Tais sistemas do saber, como a arte e a crítica, a ciência e a filosofia, o direito e a moral, na construção do projeto, separaram-se da comunicação cotidiana, abordando funções da linguagem e aspectos de validade mais estritos e unilaterais. Em razão dessa abstração, elas não podem valer já por si só como manifestações sintomáticas da decadência de uma razão centrada no sujeito (HABERMAS, 1998, p. 311 e 312).

Coelho, utilizando-se também da visão de Berman, afirma que o sentido de unidade atribuído à modernidade é algo paradoxal, porque é uma "unidade de desunidade" que nos envolve num perpétuo redemoinho de desintegração e renovação, de luta e contradição, de ambiguidade e angústia (BERMAN, 1999, apud, COELHO, 2007, p. 25).

Coelho também explica que, no sentido político, a modernidade diferencia-se do feudalismo como ciclo histórico, quando da centralização do poder político nas mãos de um soberano. Tal centralização do poder, ao articular-se à unificação dos povos unidos pela ideia de nação, e a devida institucionalização dos exércitos nacionais, a exemplo das forças militares permanentes, caracterizam o que, posteriormente, foi definido como Estado Moderno (COELHO, 2007, p. 25).

Ainda no mesmo plano político, Coelho (2007, p. 24) afirma que:

[...] a modernidade apresenta formas democráticas ou totalitárias de utopismo e voluntarismo político, as quais se articulam com um generalizado sentimento de insatisfação e alheamento que traz os germes da futura desmoralização da política como instrumento de equilíbrio social e vislumbra o fim das ideologias, processo que se agudiza ao final do período e já manifesta a mudança para a pós-modernidade, trazendo em seu bojo a política como alienação e espetáculo. 
Com esse fim das ideologias, Coelho (2007, p.23) sinaliza que o primeiro, e mais marcante traço da modernidade, é a prevalência do racionalismo como filosofia, se opondo ao obscurantismo medieval. Pode-se visualizar a manifestação deste traço em diversos setores da sociedade, tais como: na economia, por meio do capitalismo; na burocracia, como racionalização da administração; no positivismo, como racionalização da filosofia; e na dogmática, como forma de racionalizar o direito (COELHO, 2007, p. 26).

Ideologicamente, conforme explica Coelho (2007, p. 24), a modernidade se concentrou no proprietarismo, a iniciar pela apropriação dominadora da natureza, o que provocou reações de caráter coletivista, como a negação da teoria da propriedade privada, o sentimento ecológico, o humanismo, e a crença no reinado do bem e da liberdade, mas esta ideologia acarretou mal-estar, contestação, crise e falência.

Outra relevante característica da modernidade, segundo Coelho (2007, p. 24), juntamente com o racionalismo e o domínio da técnica, é o apego ao materialismo, de caráter liberal ou coletivista. Este conjuga-se à crença no progresso material, científico e social, a matematicidade, o geometrismo, o mecanicismo e a previsibilidade, favorecendo a tendência contrária ao "escapismo pseuso-espiritual", e resgatando os fantasmas da barbárie, do apocalipse, da anomia, da entropia e do caos.

Na visão de Santos (1999, p. 102), no mesmo sentido, a ideia moderna da racionalidade global da vida social e pessoal acabou se desintegrando numa imensidade de "miniracionalidades", atingindo uma irracionalidade global, inabarcável e incontrolável. A lógica de uma possível pós-modernidade de resistência se dá, portanto, na possibilidade da reinvenção dessas mini-racionalidades da vida de modo a que elas deixem de ser partes de um todo e passem a ser totalidades presentes em múltiplas partes.

A pós-modernidade, para Coelho (2007, p. 25), tem viés na superação do feudalismo e sua conversão na revolução industrial, porquanto seu principal efeito foi a possibilidade de transferência do trabalho humano para a máquina. No princípio, a máquina se limitava ao depender do homem para controlá-la. Ao entregar o controle da máquina à própria máquina, porém, faz-se um rompimento, que caracteriza a primeira aproximação à pós-modernidade, por ser uma possibilidade praticamente fantástica feita pelo aperfeiçoamento dos computadores.

A crise do projeto da modernidade, conforme Coelho (2007, p. 27), apresentou-se a partir dos anos sessenta, quando a juventude se posicionou contra as imposições ideológicas dos setores mais conservadores da sociedade, para desmistificar a racionalidade, resgatar a liberdade criativa e a espontaneidade do homem, prevalecendo os fatores humanistas, como a intuição e o sentimento. 
Por isso, o autor afirma que a principal característica da transição entre a modernidade e a pós-modernidade foi exatamente o espírito de revolta juvenil, apoiada pelos setores acadêmicos mais progressistas. No campo jurídico, a revolta se manifestou nas escolas zetéticas de interpretação jurídica, abrindo o caminho para o pensamento crítico manifestado no alternativismo jurídico-europeu (COELHO, 2007, p. 28) e, depois, no próprio nascimento de direito alternativo latino-americano, que, no ideial de Warat, estaria baseado em uma pluralidade de movimentos heterogêneos de tendências.

Tendo em vista a complexidade do projeto da modernidade, os desafios enfrentados e a sua posterior crise, Santos atenta que "o paradigma cultural da modernidade constituiu-se antes de o modo de produção capitalista se ter tornado dominante e extinguir-se-á antes de este último deixar de ser dominante" (SANTOS, 1999, p. 76).

Conforme explica Habermas, com o princípio da modernidade, são rejeitadas as consequências mutiladoras de uma auto-referência objectivante, e também as outras conotações que a subjetividade tinha uma vez acarretado em si como promessa de perspectiva de uma prática autoconsciente em que a autodeterminação solidária de todos pudesse associarse à auto-realização autêntica de cada um individualmente, promessa esta que não foi cumprida (HABERMAS, 1998, p. 310).

A extinção do projeto, conforme Santos (1999, p. 76), trata-se, em parte, de um processo de superação, uma vez que a modernidade teria cumprido algumas de suas promessas, considerando que algumas foram até mesmo cumpridas em excesso; e, em parte, um processo de obsolescência, em razão da incapacidade no cumprimento das demais promessas. Ao observar ambas as situações, Santos (1999, p. 77) afirma ser este um momento de transição nomeado de pós-modernidade inadequadamente, por não haver propriamente uma superação.

Essa extinção do projeto, para o autor (SANTOS, 1999, p. 77), significa que, pela riqueza e diversidade de novas ideias, bem como pela tentativa de articulação entre elas, o projeto apresenta complexidade interna e infinitas possibilidades, mas, exatamente por isso, propõe excesso em suas promessas, condicionando o défice em seu cumprimento. Assim, o autor (SANTOS, 1999, p. 78) afirma que “o excesso reside no próprio objetivo de vincular o pilar da regulação ao pilar da emancipação e de os vincular ambos à concretização de objetivos práticos de racionalização global da vida coletiva e da vida individual".

Este excesso caracteriza-se, assim, pela concepção de valores tais como: a justiça e autonomia; solidariedade e identidade; emancipação e subjectividade; e igualdade e liberdade. Valores estes que, como afirma Santos (1999, p. 78), são tendencialmente contraditórios, e 
resultam na falta de primazia de qualquer um deles (SANTOS, 1999, p. 78). Neste sentido, afirma Santos (1999, p. 78):

[...] cada um destes pilares assenta em lógicas ou princípios cada um deles dotado de uma aspiração de autonomia e de diferenciação funcional que, por outra via, acaba também por gerar uma vocação maximalista, quer seja, no caso do pilar da regulação, a maximização do Estado, do mercado ou da comunidade, quer seja, no caso do pilar da emancipação, a esteticização, a juridificação ou a cientificização da realidade social. Mas, a dimensão mais profunda do défice parece residir precisamente na possibilidade de estes princípios e lógicas virem humildemente a dissolver-se num projecto global de racionalização da vida social prática e quotidiana".

No tocante ao mais marcante traço da modernidade, a racionalização, Habermas (1998, p. 311) elucida que tais diferenças e antagonismos, mesmo desmoronados, encontram-se minados, a ponto de a crítica, neste cenário insosso de um mundo completamente administrado, calculado e dominado, não poder mais constituir contrastes, nuances e totalidades ambivalentes. Este nivelamento também torna-se perceptível na comparação diacrônica das formas de vida modernas e pré-modernas.

No que diz respeito aos valores, ou discursos, que basearam o projeto da modernidade, Habermas (1998, p. 309) afirma que:

Tais discursos não são vinculáveis sem ambiguidades nem à filosofia ou à ciência, nem à teoria da moral e do direito, nem mesmo à literatura ou à arte. Simultaneamente, eles opõem-se a um regresso às formas, sejam elas dogmáticas ou heréticas, no pensamento religioso.

Por sua vez, e conforme os sinais emitidos pelas sociedades capitalistas, que, mesmo passando por profundas transformações, não deixaram de ser capitalistas, Santos (1999, p.102) afirma que a conclusão mais segura a ser tirada é a de que a "pujança do capitalismo" produziu dois efeitos complementares: ao mesmo tempo em que esgotou o projeto da modernidade, o fez de tal modo que se alimenta desse esgotamento, se perpetuando nele. Por isso, "o vazio que ele produziu é tão global que não pode ser preenchido no contexto do paradigma da modernidade" (SANTOS, 1999, p.102).

Para Santos (1999, p. 102), afirmar que o projeto da modernidade se esgotou significa dizer que este cumpriu em excesso e que também criou défices irreparáveis. São eles que constituem a nossa contemporaneidade e deve-se partir para imaginar o futuro, criando as necessidades radicais, que ao serem satisfeitas, o tornarão diferente e melhor que o presente.

Em seguimento, deve-se analisar como o Estado de modelo-nacional que emergiu na Modernidade é impactado pela crise desse projeto filosófico.

\section{O FUTURO DO ESTADO COMO ATOR INTERNACIONAL}


As grandes transformações ocorridas no século passado, segundo Coelho (2007, p. 30), geralmente vinculam-se ao termo "modernidade", embora as ciências humanas caracterizem a contemporaneidade como "pós-modernidade", e esta em si já se apresenta como uma fase de transição. Tal transição, conforme o autor (COELHO, 2007, p. 30), consolida-se "à medida que se estratificam as novas formas de vida social desenvolvidas nesse período", perdendo as características historiográficas que a atribuíram a terminologia de pós-modernidade, transformando-as em uma nova fase, a transmodernidade. Neste sentido, sustenta Coelho (2007, p. 30):

A transmodernidade se distingue da modernidade e da pós-modernidade na medida em que alude a uma fase de transição para um futuro ainda não definido, mas que, desde logo, envolve aspectos que levam a uma superação dos velhos paradigmas de comportamento individual e coletivo, e dos modelos de saber já consolidados como algo produzido pela modernidade.

Desta forma, a transmodernidade passa a ser compreendida como "antecipação de um futuro que, antes vivenciado na ficção, nas profecias conjeturas e utopias, já se apresenta como definitivo, a catalisar as energias da humanidade" (COELHO, 2007, p.30). A pósmodernidade, por sua vez, se conecta com a difusão de diversos elementos, tais como novas formas de organização empresarial, urbana e familiar, articulando-se com a globalização e permeando espaços econômicos, políticos e jurídicos da sociedade. Desta forma, ela se expressa na busca de maior igualdade de oportunidades e de mercados, bem como maior anseio de democracia e justiça social (COELHO, 2007, p. 34).

Como exposto, os pilares da regulação e da emancipação sustentaram o edifício da Modernidade, mas, com sua posterior crise e os fenômenos da pós-modernidade e transmodernidade, as dinâmicas da sociedade contemporânea se alteram, refletindo diretamente no papel do Estado como ator internacional. Neste sentido, Coelho (2007, p. 30) explica que a superação dos modelos epistêmicos tradicionais é uma consequência da crise da modernidade, afirmando um novo paradigma no atual horizonte das ciências sociais.

A modernidade do Estado constitucional do século XIX, para Santos (2000, p. 117), caracterizou-se pela sua organização formal, unidade interna e soberania absoluta dentro de um sistema de Estados e, especialmente, pela unificação e centralização de seu sistema jurídico, que, transformado em linguagem universal, faz a comunicação do Estado com a sociedade civil. Desta forma, para Santos (2000, p. 117), quando comparado com a sociedade civil, o Estado torna-se uma realidade construída, uma criação artificial e moderna.

Esta separação entre Estado e sociedade civil engloba duas ideias opostas. A primeira, de um Estado mínimo, e a segunda, de um Estado máximo, o que, simultaneamente com a ação estatal, passa a ser considerado como um inimigo potencial da liberdade individual e como vol.09, n. 03, Rio de Janeiro, 2016. pp. 
condição para seu exercício (SANTOS, 2000, p. 118). Para Santos (2000, p. 118) isso ocorre porque "o Estado enquanto realidade construída é a condição necessária da realidade espontânea da sociedade civil”".

Esta consolidação ideológica do Estado moderno, como forma de substituir os velhos fantasmas da Idade Média e a ascensão dos ideais de liberdade e igualdade consagrados nos códigos e nas declarações universais de direitos, tornou-se o auge do processo que conduziu à transmodernidade (COELHO, 2007, p. 111).

Neste processo, paralelamente à ideia de afirmar o Estado como pressuposto de direito, desenvolveu-se uma ideologia buscando tirar o homem, a sociedade e o próprio Estado de seu contexto social-histórico, colocando-os em uma situação de "a-historicidade". Assim explica Coelho (2007, p. 111):

O Estado como símbolo da dominação social real sai de si para coisificar-se no imaginário metafísico que o legitima, para depois retomar sua própria ideia, dispensando a legitimação externa a ele, pois se auto-institui como entidade por si mesma legítima e triunfante em sua tarefa de ocupação de todos os espaços normativos da sociedade alienada.

Ainda, no tocante à transição da pós-modernidade para a transmodernidade, Coelho (2007, p. 36) enfatiza que alguns fatores como a globalização, o domínio da informação e o binômio capitalismo/neoliberalismo "impregnaram" a pós-modernidade, acelerando esta transição. Um destes fatores citados por Coelho, a globalização, é um fenômeno dinâmico, complexo e multifacetado, que coloca o Estado em uma sociedade internacional reconfigurada, alterando, consequentemente, o seu papel. Neste sentido, explica Olsson (2005, p. 172):

[...] para os Estados e as organizações intragovernamentais, a globalização implicou a redefinição dos seus papeis o novo cenário instituído, uma vez que são entidades anteriores ao processo globalizante em marcha no perfil ora empregado [...].

$\mathrm{Na}$ abordagem clássica, o papel do Estado relaciona-se diretamente às próprias diversidades objetivas dos Estados entre si, porque, a princípio, os Estados são simetricamente soberanos, detendo direitos e deveres iguais no âmbito internacional (OLSSON, 2005, p. 173). Mas, ao analisar estes Estados pela ótica da sociedade internacional, conforme Olsson (2005, p. 173), "suas diferenças entre fatores objetivos, como econômicos, sociais e naturais, por exemplo, e as decorrentes variações na sua importância de atuação no meio internacional suscitam o debate sobre uma possível hierarquia entre os Estados".

Sendo o Estado o mais tradicional ator internacional, a sua emergência vincula-se à formação da sociedade internacional, que, não por acaso, é historicamente "entre nações". Deste modo, a percepção inicial de uma sociedade internacional constituiu-se com a emergência do Estado-nação como modelo político-jurídico largamente difundido (OLSSON, 
2007, p. 292), como um projeção global de uma sociedade de Leviatãs, à simetria de uma sociedade civil nacional.

Coelho (2007, p. 37), ao seu turno, explica que o incremento do comércio internacional favoreceu o relacionamento entre Estados, mas atenta ao fato de que este comércio também estava associado às "práticas predatórias" da conquista territorial e da imposição de formas de troca que acabaram por beneficiar alguns países e populações, em detrimento de outros. Estes Estados prejudicados viam sua economia imersa em um processo de estagnação, de transformação muito lenta, e até mesmo de retrocesso, o que fez com que a internacionalização se transformasse em colonização e imperialismo (COELHO, 2007, p. 37). Não por acaso, as Relações Internacionais tiveram no paradigma da dependência e suas variantes, como o desenvolvimento dependente ou o subdesenvolvimento dependente, por exemplo, um referencial teórico muito importante para o diagnóstico dessa realidade no viés econômico na segunda metade do século XX (CARDOSO, FALETTO, 1970, p. 46).

O incremento do comércio internacional e a emergência de novos centros de produção normativa, dotados de um poder de coerção mais eficiente, centrados no controle específico da economia da nação, paralelos ao Estado, leva a teoria pluralista a recepcionar outros fundamentos, condizentes com a dimensão política da transmodernidade (COELHO, 2007, p. 131). Neste sentido, Olsson (2003, p. 167) indica:

A expansão da atividade econômica no modo de produção capitalista revelase progressivamente acentuada e ultrapassa as fronteiras nacionais na busca de novos mercados. No seu bojo, grandes empresas foram ocupando espaço, em número e em dimensões cada vez maiores. Essas empresas, por vezes compreendidas como multinacionais, ou trasnacionais ou supranacionais, revelam-se interlocutoras poderosas no palco internacional, em face de sua capacidade de articulação concentrada de investimento massivo e de circulação de riqueza.

O Estado, ao assumir seu papel na sociedade internacional (ou "sistema de governo internacional", como preferem Hirst e Thompson), integra a categoria de ator internacional em conjunto com o restante do cenário onde as relações internacionais realizam-se. Isso pressupõe sua inserção na problemática das relações internacionais como uma das suas bases estruturais (OLSSON, 2003, p. 150). Para o autor, também devem ser reconhecidos como atores na sociedade internacional mundializada contemporânea outros agentes de relações ou fluxos de projeção global, em especial as organizações internacionais não-governamentais e as empresas transnacionais (OLSSON, 2003, p. 154), o que reforça o caráter não mais exclusivamente estatal dos protagonismos. Os atores não-estatais são cada vez mais presentes e importantes na sociedade globalizada contemporânea. 
Neste mesmo sentido, Olsson (2007, p. 323) enfatiza que a expressão “transnacionalidade" refere-se à característica da não-vinculação da administração da empresa a interesses nacionais específicos, também desconsiderando qualquer restrição territorial de atuação, posicionando-se "acima" e "além" de qualquer recorte geográfico nas suas atividades. O caráter transnacional dessas novas relações empresariais das grandes corporações evidencia um protagonismo claramente apátrida no investimento e na gestão de seus recursos produtivos, em que a busca de vantagens comparativas dinâmicas segue padrões de racionalidade econômica puramente instrumental, a despeito de conexões pessoais ou valores nacionais.

A emergência de mercados internacionais e outros processos econômicos, segundo Hirst e Thompson (1998, p. 264), envolvem os principais governos nacionais em um novo papel, deixando de funcionar como entidades "soberanas" para assumir o papel de componentes de um "sistema de governo" internacional. Para os autores, devido a essa troca de papel, "as funções centrais do Estado-nação tornar-se-ão as de prover legitimidade aos mecanismos de governabilidade supranacionais e subnacionais e garantir a responsabilidade por eles" (HIRST; THOMPSON 1998, p. 264).

Todos estes fatores fazem com o que o panorama político da transmodernidade permaneça paradoxal, conforme aduz Coelho (2007, p. 113), especialmente quando se constata, que, apesar dos inúmeros fatores que conduziram à transmodernidade, ou até mesmo em função deles, a sociedade tem se tornado homogênea pela informação, destituindo os membros desta sociedade de ambições dirigidas a valores transcendentais, e voltando-se ao imediatismo de bens materiais e prestígio social que aparentemente somente o dinheiro consegue proporcionar.

Este panorama político e seus fatores acarretam inúmeras mudanças no papel do Estado. Coelho (2007, p. 131) resume na ideia de "minimização da soberania interna, enquanto poder de fazer as leis, e externa, enquanto autonomia no concerto das nações”, resultando em sua transformação enquanto unidade ôntica e consolidando a organização social.

Para Olsson (2005, p. 145), se a soberania embasa os limites do recorte territorial, a consolidação de uma instância supranacional plena, necessariamente, subentende uma renúncia ou cessão, ainda que parcialmente, da soberania das unidades estatais sobre seus territórios ou pessoas nacionais. Neste sentido, para Coelho (2007, p. 139), no lugar de propor um Estado do futuro, pode-se pensar em uma organização política nucleada em comunidades menores, não mais vinculadas pela submissão ou lealdade a um poder singular. A relativização da soberania e da autonomia do Estado moderno, na mesma linha, para Bedin (2001, p. 348) trata-se de um 
dos acontecimentos mais importantes da sociedade internacional contemporânea a partir da estruturação da era da globalização.

Os fatos que ultrapassam os limites soberanos dos Estados estão diretamente relacionados com a globalização devido ao aumento do volume e da intensidade dos fluxos ou relações entre os Estados, tais como econômicas, políticas, culturais e jurídicas. Neste contexto, encontra-se especialmente o aumento na intensidade destes fluxos ou relações entre outros protagonistas emergentes, como organizações não-governamentais e corporações transnacionais. Por sua vez, isso torna-se possível graças à constante evolução das tecnologias de telecomunicações e informática, que trouxeram consigo não apenas a relativização das fronteiras nacionais, a exemplo do caso do capital financeiro, mas também a consciência da problemática do mundo de forma integral, a exemplo dos problemas ambientais (OLSSON, 2005, p. 146). O mundo novo, admirável ou não, é cada vez mais próximo à visionária "aldeia global" (MCLUHAN, 1998, p. 22).

O Estado moderno, para Hirst e Thompson (1998, p. 263), é um fenômeno relativamente recente, em que a soberania se torna uma exigência política singular para o controle exclusivo de um território definido. Neste mesmo sentido, Bedin (2001, p. 339), referindo-se ao Estado moderno, explica que, mesmo com o fenômeno da globalização, o Estado em si não desapareceu, tampouco desaparecerá de forma abrupta, mas sim adquiriu novas funções e um novo estatuto jurídico e político.

A formação de uma instância supranacional plena eleva a compreensão do mundo e de seus problemas mais amplos acima dos marcos nacionais. A amplitude deste fenômeno desloca o eixo analítico para fora do Estado, ainda que seu papel continue em destaque. Tal deslocamento pode estar relacionado com uma incapacidade involuntária gerencial do Estado, seja ou por estar diretamente envolvido como interessado na resolução dos conflitos entre os próprios Estados, ou porque os efeitos ultrapassam seus limites soberanos, como questões as ecológicas, da mobilidade do capital financeiro ou do terrorismo e das organizações criminosas internacionais (OLSSON, 2005, p. 145).

Esse conjunto de fatores implica na tendencial redução do papel do Estado ao simples controle bélico e legal sobre o território, e a consequente relativização do significado da soberania, principalmente por conta da globalização da economia e da política e pelo elevado custo de confrontos no nível nuclear (OLSSON, 2005, p. 175). Por isso, parece haver um igual deslocamento do papel da guerra, que até então estava no centro do exercício da soberania, conforme explicam Hirst e Thompson (1998, p. 275): “do século XVI até hoje, a principal capacidade que define o Estado moderno tem sido o poder de guerrear e de usar as vidas e a vol.09, n. 03, Rio de Janeiro, 2016. pp. 
propriedade de seus cidadãos para isso". O poder das armas e dos tanques não parece ser capaz de enfrentar os novos desafios da sociedade globalizada, com fluxos transnacionais que ignoram limites territoriais e deslocam-se dinamicamente por todo o globo.

Devido a essa sequência de fenômenos interligados, e também ao reconhecimento do poder econômico expressivo das transnacionais, considerando a sua capacidade de investimentos e de mobilização de capital, a ideia estatocêntrica perde espaço para uma ideia de interpenetração dos papeis dos atores no cenário internacional ou de interdependência complexa. Esse novo cenário posiciona as empresas transnacionais com poder similar ao Estado em áreas temáticas específicas, especialmente tendo em vista seu capital equivalente ou até superior a algumas nações (OLSSON, 2005, p. 182).

\section{CONCLUSÃO}

A modernidade foi sustentada por três princípios essenciais: O Estado, a Sociedade, a Economia Liberal. O primeiro deles, o Estado, apresentou uma nova formulação de organização e de exercício do poder político da sociedade, tendo em vista que o esgotamento modelo Medieval abriu a oportunidade de emergência de novas relações de poder. O segundo, a Sociedade, constitui a reformulação das relações sociais, devido ao esgotamento do paradigma até então centrado em organizações de produção hierarquizadas e servis nos feudos. E, por fim, o pilar da Economia Liberal, fez com que o capitalismo e a classe burguesa emergissem, porque a estrutura dos feudos em relações predominantemente de troca não acompanhava mais a complexidade crescente da vida social e econômica.

Desde a sua concepção, o projeto da Modernidade apresentou pontos sensíveis que desembocaram em sua posterior crise, ou esgotamento. As promessas da Modernidade, de uma sociedade de liberdade, igualdade e fraternidade, como proclamam os ideários nacionais desde então, parecem cada vez mais distantes, já irrealizadas e potencialmente irrealizáveis. De certa forma, é como se o próprio rol de características da modernidade, com a crença no progresso material, científico e social, a matematicidade, o geometrismo, o mecanicismo e a previsibilidade, acabasse por resgatar os fantasmas da barbárie, do apocalipse, da anomia, da entropia e do caos da era Medieval. Não por a caso, essa ideia moderna de racionalidade global da vida social e pessoal, como adverte Santos (1999, p. 102), acabou se desintegrando numa imensidade de "mini-racionalidades", atingindo uma incontrolável irracionalidade global, e tornando em si mesmo o projeto da modernidade incompletável.

A afirmação da pós-modernidade e da transmodernidade, por sua vez, como uma espécie de resposta a essa realidade desafiadora, incorpora variáveis novas, como a 
globalização, o domínio da informação e o binômio capitalismo/neoliberalismo, que “impregnaram” a pós-modernidade e aceleraram o processo de transição.

Frente a isso, conclui-se que o papel do Estado se modificou sensivelmente nessa nova realidade da sociedade internacional globalizada. O Estado-nação, até então definido como um ente totalmente soberano, detentor de direitos e deveres igualmente a todos os demais Estados co-irmãos, já, com esta transição, passou a integrar uma sociedade internacional hierarquizada em critérios variados, notadamente econômicos. O incremento do comércio internacional e a ascensão das empresas transnacionais com fluxos para além dos limites dos Estados, por sua vez, provocou a relativização da soberania estatal e a redefinição dos papéis até então inquestionáveis para um futuro até agora de desfecho incerto.

\title{
THE PHILOSOPHICAL PROJECT OF MODERNITY CRISIS AND FUTURE OF NATION STATE AS INTERNATIONAL ACTOR
}

\begin{abstract}
The article aims to study philosophical project of modernity building and its cornerstones, its current crisis and impacts in state role as international actor. The work analyses each of modernity cornerstones, and how their building leaves in the project lacks not able to be fulfilled, that is up to now an unfinished project but also not anymore able to be finished. Study shows that changes in modernity cornerstones impact international dynamic year by year and therefore the nation state itself. The conclusion is that sovereignty is being reshaped and corporations are challenging the up to now hegemonic power of States, now unable to answer to this new claims of power with traditional tools of state politics in the way of uncertain future.
\end{abstract}

Keywords: Modernity. Modernity crisis. International actor. Nation state. Future of State.

\section{REFERÊNCIAS}

BEDIN, Gilmar Antonio.A sociedade internacional e o século XXI: em busca da construção de uma ordem judicial justa e solidária. Ijuí: Ed. Unijuí, 2001.

BERMAN, Marshall. Tudo que é Sólido se Desmancha no Ar. Tradução de Carlos Felipe Moisés e Ana Maria L. loriatti. 16. Raimp. São Paulo: Cia das Letras, 1999.

CARDOSO, Fernando Henrique; FALETTO, Enzo. Dependência e desenvolvimento na América Latina: ensaio de interpretação sociológica. 7. ed. Rio de Janeiro: LTC, 1970. COELHO, Luiz Fernando Coelho. Saudade do Futuro. Curitiba: Juruá, 2007. 
HABERMAS, Jurgen. O discurso filosófico da modernidade. Trad. Ana Maria Bernardo et al. Lisboa: Dom Quixote, 1998.

HIRST, Paul; THOMPSON, Grahame. Globalização em questão: a economia internacional e as possibilidades de governabilidade. Trad. Wanda Caldeira Brandt. Petrópolis, RJ: Vozes, 1998.

HOBBES, Thomas. Leviatã: ou matéria, forma e poder de um estado eclesiástico e civil. Trad. Rosina D Angina. 2 ed. São Paulo: Martin Claret, 2012.

LOCKE, John. Segundo tratado sobre o governo civil: ensaio sobre a origem, os limites e os fins verdadeiros do Governo Civil. Trad. Magda Lopes e Marisa Lobo da Costa. Petrópolis, RJ: Vozes, 1994.

MCLUHAN, Marshall. Os meios de comunicação como extensões do homem. Trad. Décio Pignatari. 9. ed. São Paulo: Cultrix, 1998.

OLSSON, Giovanni. Relações Internacionais e seus atores na Era da Globalização. Curitiba: Juruá, 2005.

OLSSON, Giovanni. Poder político e sociedade internacional contemporânea: governança global com e sem governo e seus desafios e possibilidades. Ijuí: Ed. Unijuí, 2007.

ROUSSEAU, Jean-Jacques. Discurso sobre a economia política e do Contrato Social. Trad. Maria Constança Peres Pissarra. Petrópolis: Vozes, 1996.

SANTOS, Boaventura de Sousa. Pela mão de Alice: o social e o político na pósmodernidade. 5. Ed. São Paulo: Cortez, 1999.

SMITH, Adam. A riqueza das nações. São Paulo: Nova Cultural, 1996. Coleção Os Economistas.

WARAT, Luis Alberto; PÊPE, Albano Marcos Bastos. Filosofia do direito: uma introdução crítica. São Paulo: Moderna, 1996.

Trabalho enviado em 29 de janeiro de 2016.

Aceito em 06 de março de 2016. 